\title{
Aliskiren reduces the release of soluble (pro)renin receptor from human umbilical vein endothelial cells
}

\author{
SHINJI YAMASHITA ${ }^{1}$, KAZAL BORON BISWAS ${ }^{2}$, A.H.M. NURUN NABI ${ }^{3}$, \\ TSUTOMU NAKAGAWA ${ }^{2}$, FUMIAKI SUZUKI ${ }^{2}$ and AKIO EBIHARA ${ }^{2,4}$ \\ ${ }^{1}$ United Graduate School of Agricultural Science; ${ }^{2}$ Laboratory of Biological Chemistry, Faculty of Applied \\ Biological Sciences, Gifu University, Gifu 501-1193, Japan; ${ }^{3}$ Laboratory of Population Genetics, Department \\ of Biochemistry and Molecular Biology, University of Dhaka, Dhaka 1000, Bangladesh; ${ }^{4}$ Center for Highly \\ Advanced Integration of Nano and Life Sciences, Gifu University (G-CHAIN), Gifu 501-1193, Japan
}

Received March 15, 2018; Accepted July 2, 2018

DOI: $10.3892 /$ br.2018.1124

\begin{abstract}
Pro)renin receptor [(P)RR] has been implicated in diverse biological processes through binding to its ligands, which include renin, prorenin, Wnt signaling molecules and subunits of vascular $\mathrm{H}^{+}$-ATPase. Recent studies have reported that $(\mathrm{P}) \mathrm{RR}$ is implicated in pathophysiological conditions including retinopathy and pancreatic ductal adenocarcinoma, and the soluble form of this receptor $[\mathrm{s}(\mathrm{P}) \mathrm{RR}]$ is considered as a useful biomarker for diseases. The present study examined the effect of aliskiren, the first orally active direct renin inhibitor, on the protein levels of (P)RR using cultured human umbilical vein endothelial cells (HUVECs). The cells were treated with or without aliskiren $(10 \mathrm{nM})$ at $37^{\circ} \mathrm{C}$ for different durations $(0,8,16$ and $24 \mathrm{~h})$. Aliskiren-treated HUVECs exhibited reduced proliferation compared with those treated without the drug. Furthermore, aliskiren treatment decreased not only the level of exogenous prorenin that bound to the membranes of HUVECs, but also the renin activity derived from this binding activity. These results indicate that the quantity of full-length (P)RR was reduced by aliskiren treatment, and furthermore, that the level of $\mathrm{s}(\mathrm{P}) \mathrm{RR}$ released from HUVECs was decreased
\end{abstract}

Correspondence to: Professor Akio Ebihara, Laboratory of Biological Chemistry, Faculty of Applied Biological Sciences, Gifu University, 1-1 Yanagido, Gifu 501-1193, Japan

E-mail: aebihara@gifu-u.ac.jp

Abbreviations: AngI, angiotensin I; AOG, angiotensinogen; $\mathrm{CHO}$, Chinese hamster ovary; $\mathrm{C}_{\mathrm{In}}$, initial concentration of prorenin; $\mathrm{C}_{\mathrm{UB}}$, concentration of unbound prorenin; DMEM, Dulbecco's modified Eagle's medium; ELISA, enzyme-linked immunosorbent assay; FBS, fetal bovine serum; HBS, 2-[4-(2-hydroxyethyl)-1-piperazinyl]ethanesulfonic acid-buffered saline; HEPES, 2-[4-(2-hydroxyethyl)-1-piperazinyl]ethanesulfonic acid; HUVEC, human umbilical vein endothelial cell; (P)RR, (pro) renin receptor; $\mathrm{s}(\mathrm{P}) \mathrm{RR}$, soluble (pro)renin receptor

Key words: aliskiren, soluble (pro)renin receptor, prorenin, human umbilical vein endothelial cells with the treatment. Recent study has reported that $s(P) R R$ exerted antidiuretic function. The current study suggests that the levels of $\mathrm{s}(\mathrm{P}) \mathrm{RR}$, as a potential antidiuretic molecule and prospective disease biomarker, may be decreased during anti-hypertensive treatments with aliskiren.

\section{Introduction}

(Pro)renin receptor $[(\mathrm{P}) \mathrm{RR}]$ is a single-spanning membrane protein comprised of 350 amino acid residues (1-3). (P)RR is coded by the ATP6AP2 gene, which is located on the X chromosome at locus p11.4 (NCBI gene ID: 10159). Although (P)RR was originally identified as a regulator of the renin-angiotensin system essential for maintaining blood pressure and fluid balance, angiotensin-independent functions of (P)RR have been reported, including functions as an accessory protein of the vacuolar $\mathrm{H}^{+}$-ATPase (4) and a cofactor of the Wnt receptor complex (5). Other studies have indicated that $(\mathrm{P}) \mathrm{RR}$ is also implicated in pathophysiological conditions including retinopathy (6), nephropathy (7), mental retardation (8) and pancreatic ductal adenocarcinoma (9).

(P)RR undergoes intracellular processing to produce three different forms: A full-length form $(1,2)$, a truncated membrane-bound form (10) and a truncated soluble form without the transmembrane domain termed soluble (P)RR [s(P)RR] $(11,12) . \mathrm{s}(\mathrm{P}) \mathrm{RR}$ has been detected in plasma (11) and urine (13). In patients with essential hypertension, serum $\mathrm{s}(\mathrm{P}) \mathrm{RR}$ levels have been associated with various types of renal dysfunction (14). Additionally, previous study identified significantly higher plasma concentrations of $s(P)$ $\mathrm{RR}$ in patients with pancreatic ductal adenocarcinoma than in healthy controls (9). Lu et al (15) reported that $\mathrm{s}(\mathrm{P}) \mathrm{RR}$ exerted antidiuretic action via frizzled- 8 dependent $\beta$-catenin signaling, which leads to enhanced renal aquaporin-2 expression and urine concentrating capability. These authors first proposed the physiological role of $s(P) R R$ in regulating fluid homeostasis (15), and in turn, $\mathrm{s}(\mathrm{P}) \mathrm{RR}$ in body fluids has been proposed as a useful biomarker for diseases $(9,14)$ as well as an indicator of physiological function (15).

Aliskiren is an orally-active direct renin inhibitor (16). It specifically binds to the active site of human renin, which 
catalyzes the rate-limiting step of the renin-angiotensin system (16). This medicine is prescribed to patients with mild to moderate hypertension (17). Aliskiren has been reported to reduce $(\mathrm{P}) \mathrm{RR}$ expression in the renal compartments of streptozotocin-induced diabetic rats (18), and also in cultured human aortic smooth muscle cells (19). However, little is known about the effect of aliskiren on the concentration of $\mathrm{s}(\mathrm{P}) \mathrm{RR}$ in body fluids.

Our group previously reported that $\mathrm{s}(\mathrm{P}) \mathrm{RR}$ was released from cultured human umbilical vein endothelial cells (HUVECs) (20), which can be used as an in vitro model to investigate general properties of the human endothelium (21). In the present study, the effect of aliskiren on the protein levels of $\mathrm{s}(\mathrm{P}) \mathrm{RR}$ released from cultured HUVECs was examined.

\section{Materials and methods}

Preparation of recombinant proteins. Recombinant human prorenin was expressed in Chinese hamster ovary $(\mathrm{CHO})$ cells and purified as previously described (22). In brief, cells harboring cDNA coding for human prorenin were cultured in Dulbecco's modified Eagle's medium (DMEM; Nissui Pharmaceutical Co., Ltd., Tokyo, Japan) supplemented with $5 \%$ fetal bovine serum (FBS; PAA Laboratories $\mathrm{GmbH}$, Pasching, Austria), $0.1 \mathrm{mM}$ non-essential amino acids (Gibco; Thermo Fisher Scientific, Inc., Waltham, MA, USA), 2 mM glutamine, $100 \mathrm{U} / \mathrm{ml}$ streptomycin and $0.6 \mathrm{mM}$ methotrexate. The cells were maintained at $37^{\circ} \mathrm{C}$ under $5 \% \mathrm{CO}_{2}$ in $25-\mathrm{cm}^{2}$ cell culture flasks (CELLSTAR ${ }^{\circledR}$; Greiner Bio-One GmbH, Frickenhausen, Germany) until they were $100 \%$ confluent. Human prorenin was purified from the $\mathrm{CHO}$ cell conditioned medium by cation-exchange chromatography on a Resource S column (GE Healthcare, Amersham, UK). The concentration of purified prorenin was measured using a human prorenin enzyme-linked immunosorbent assay (ELISA) kit (cat no. IHPRENKT-NP; Innovative Research, Inc., Novi, MI, USA). Prior to experimentation, purified prorenin was incubated at $37^{\circ} \mathrm{C}$ for $1 \mathrm{~h}$ (23) to avoid cryo-activation due to preservation (24). Recombinant sheep angiotensinogen (AOG) was also expressed in $\mathrm{CHO}$ cells and purified as previously described $(25,26)$.

Culture of HUVECs. HUVECs (cat no.: KJB-110; DS Pharma Biomedical Co., Ltd., Osaka, Japan) were cultured in human endothelial cell medium (DS Pharma Biomedical Co., Ltd.) supplemented with $2 \%$ FBS, essential endothelial growth factors (included in the endothelial cell medium), $0.1 \%$ heparin, $1 \%$ ascorbic acid, $0.04 \%$ hydrocortisone and $0.1 \%$ gentamicin/amphotericin-1000. The cells were maintained at $37^{\circ} \mathrm{C}$ under $5 \% \mathrm{CO}_{2}$ in $25-\mathrm{cm}^{2}$ cell culture flasks (CELLSTAR ${ }^{\circledR}$ ) until they were $80-90 \%$ confluent.

Treatment of HUVECs with aliskiren. HUVECs were seeded at a density of 150,000 cells/well in 12-well sterile plates, and incubated at $37^{\circ} \mathrm{C}$. After $24 \mathrm{~h}$, the medium was removed, and the cells were washed with 2-[4-(2-hydroxyethyl)-1-piperazinyl]ethanesulfonic acid (HEPES)-buffered saline [(HBS); $1.0 \mathrm{~g} / \mathrm{l}$ dextrose, $5.0 \mathrm{~g} / \mathrm{l} \mathrm{HEPES}, 0.37 \mathrm{~g} / 1 \mathrm{KCl}, 8.0 \mathrm{~g} / 1 \mathrm{NaCl}$ and $0.14 \mathrm{~g} / 1 \mathrm{Na}_{2} \mathrm{HPO}_{4} \cdot 2 \mathrm{H}_{2} \mathrm{O}, \mathrm{pH}$ 7.4]. The cells were then treated with or without aliskiren (10 nM; Novartis Pharma AG, Basel,

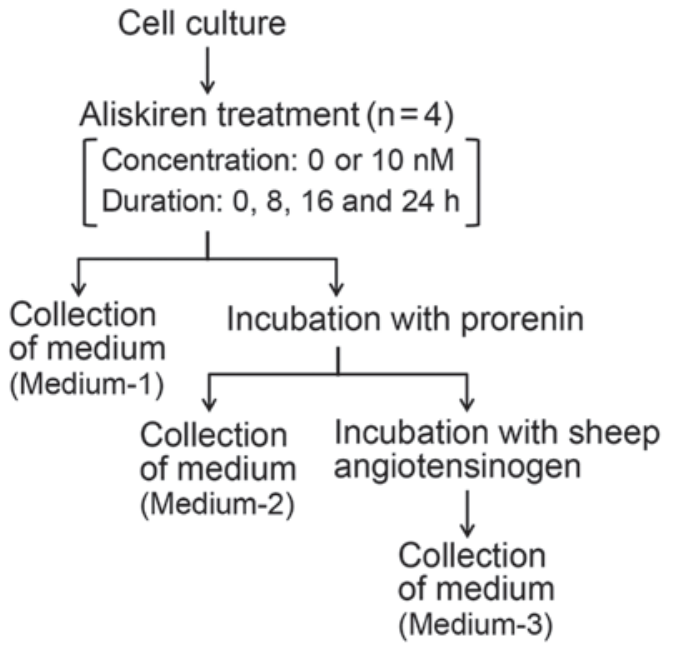

Figure 1. Treatment protocol of human umbilical vein endothelial cells. Medium-1-3 were collected and used for determining the concentrations of soluble (pro)renin receptor, unbound prorenin and angiotensin I, respectively.

Switzerland) at $37^{\circ} \mathrm{C}$ for different durations $(0,8,16$, and $24 \mathrm{~h})$ in FBS-free DMEM (Fig. 1). Following each completed duration of treatment: i) the cultured medium (hereafter referred to as Medium-1) was collected to determine the concentration of $s(\mathrm{P}) \mathrm{RR}$, and the cells were washed 3 times with HBS and incubated at $37^{\circ} \mathrm{C}$ with prorenin $(1.0 \mathrm{nM})$ for $1 \mathrm{~h}$; ii) the medium containing the unbound prorenin (hereafter referred to as Medium-2) was collected, and the cells were further washed 3 times with HBS and incubated at $37^{\circ} \mathrm{C}$ with sheep AOG $(0.3 \mu \mathrm{M})$ for $30 \mathrm{~min}$ in $5 \mathrm{mM}$ sodium phosphate buffer (pH 7.2) containing $5 \mathrm{mM}$ diisopropyl fluorophosphates, $5 \mathrm{mM}$ EDTA, $100 \mathrm{mM} \mathrm{NaCl}$ and $0.1 \%$ (w/v) bovine serum albumin fraction V (Roche Diagnostics GmbH, Mannheim, Germany); and finally iii) the medium containing the possible generated angiotensin I (AngI; hereafter referred to as Medium-3) was collected. These experimental procedures are depicted in Fig. 1. The cells treated without aliskiren served as controls.

For cell counting, HUVECs were seeded, cultured and treated with or without aliskiren, as described above. After each duration of treatment, the total number of cells per well was counted using a hemocytometer. This cell culture was performed independently of collecting the three media described above.

Determination of concentration of membrane-bound prorenin in HUVECs. The concentration of prorenin contained in Medium-2 was determined using the human prorenin ELISA kit, and was considered as the concentration of unbound prorenin $\left(\mathrm{C}_{\mathrm{UB}}\right)$. The percentage of prorenin bound to the cell membrane was calculated using the following equation: $\left(\mathrm{C}_{\mathrm{In}}-\mathrm{C}_{\mathrm{UB}}\right) / \mathrm{C}_{\mathrm{In}} \times 100$, where $\mathrm{C}_{\mathrm{In}}$ was the initial concentration of prorenin that was incubated with HUVECs (1.0 nM).

Measurement of renin activity derived from membrane-bound prorenin in HUVECs. The concentration of AngI in Medium-3 was determined by ELISA using an assay developed and prepared in our laboratory (27). The AngI concentration was divided by the reaction time $(30 \mathrm{~min})$ to calculate renin activity. 


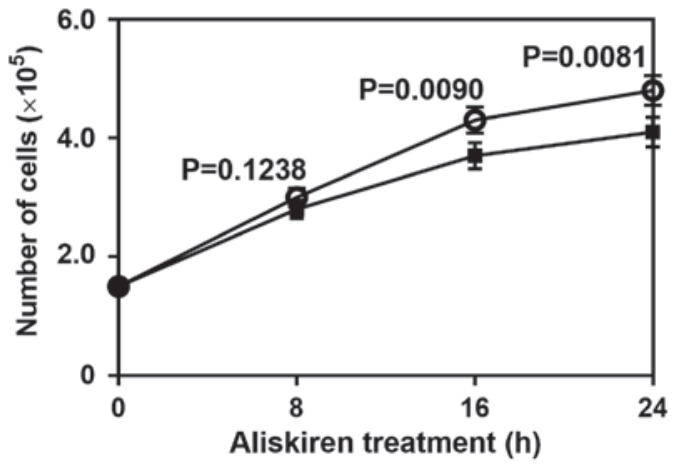

Figure 2. Effect of aliskiren on the growth of HUVECs. HUVECs were cultured for different durations in the presence (filled squares) or absence (open circles) of aliskiren. Following each incubation time, the total number of cells per well was counted using a hemocytometer. Statistical differences were identified between aliskiren-treated cells and controls by a two-tailed unpaired Student's t-test with $\mathrm{P}<0.05$ as the limit of significance. HUVEC, human umbilical vein endothelial cell.

Determination of $s(P) R R$ concentration in the culture medium of HUVECs. The concentration of $\mathrm{s}(\mathrm{P}) \mathrm{RR}$ contained in Medium-1 was determined by sandwich ELISA using an assay developed and prepared in our laboratory (20) with a primary anti-(P)RR antibody (anti-human renin $\mathrm{R}$ polyclonal antibody; cat no. AF5716; R\&D systems, Inc., Minneapolis, MN, USA) and a secondary anti-(P)RR antibody [biotin-labeled anti-237/250-antibody (20)]. The resulting antigen-antibody complex was tagged with a high-sensitivity streptavidin-horseradish peroxidase conjugate, and detected by a chromogenic reaction using hydrogen peroxide and 3,3',5,5'-tetramethylbenzedine. The $\mathrm{s}(\mathrm{P}) \mathrm{RR}$ standards were prepared as previously described (28).

Statistical analysis. GraphPad Prism 7.0 software (GraphPad Software, Inc., La Jolla, CA, USA) was used to analyze the data. Data were expressed as the mean \pm standard deviation of four replicates for each treatment. The propagation of error formula (29) was used to calculate the standard deviation of either of three ratio values: bound prorenin per cell, renin activity per cell and $\mathrm{s}(\mathrm{P}) \mathrm{RR}$ per cell. A two-tailed unpaired Student's t-test was performed to compare between two groups (aliskiren-treated cells and controls). $\mathrm{P}<0.05$ was considered to indicate statistical significance.

\section{Results}

Effect of aliskiren on the growth of HUVECs. HUVECs were cultured in the presence or absence of aliskiren. The cell number of aliskiren-treated HUVECs was lower than that of the controls, most notably at $16 \mathrm{~h}(\mathrm{P}=0.0090)$ and $24 \mathrm{~h}$ $(\mathrm{P}=0.0081$; Fig. 2). Thus, aliskiren appeared to reduce the growth of HUVECs.

Effect of aliskiren on the cell-surface expression of full-length $(P) R R$. (P)R R binds renin and its inactive precursor, prorenin (1-3). To estimate the expression of full-length (P) $\mathrm{RR}$ on the plasma membrane of HUVECs, recombinant prorenin (exogenous prorenin) was added to the culture medium (Fig. 1), and the amount of prorenin bound to the cell
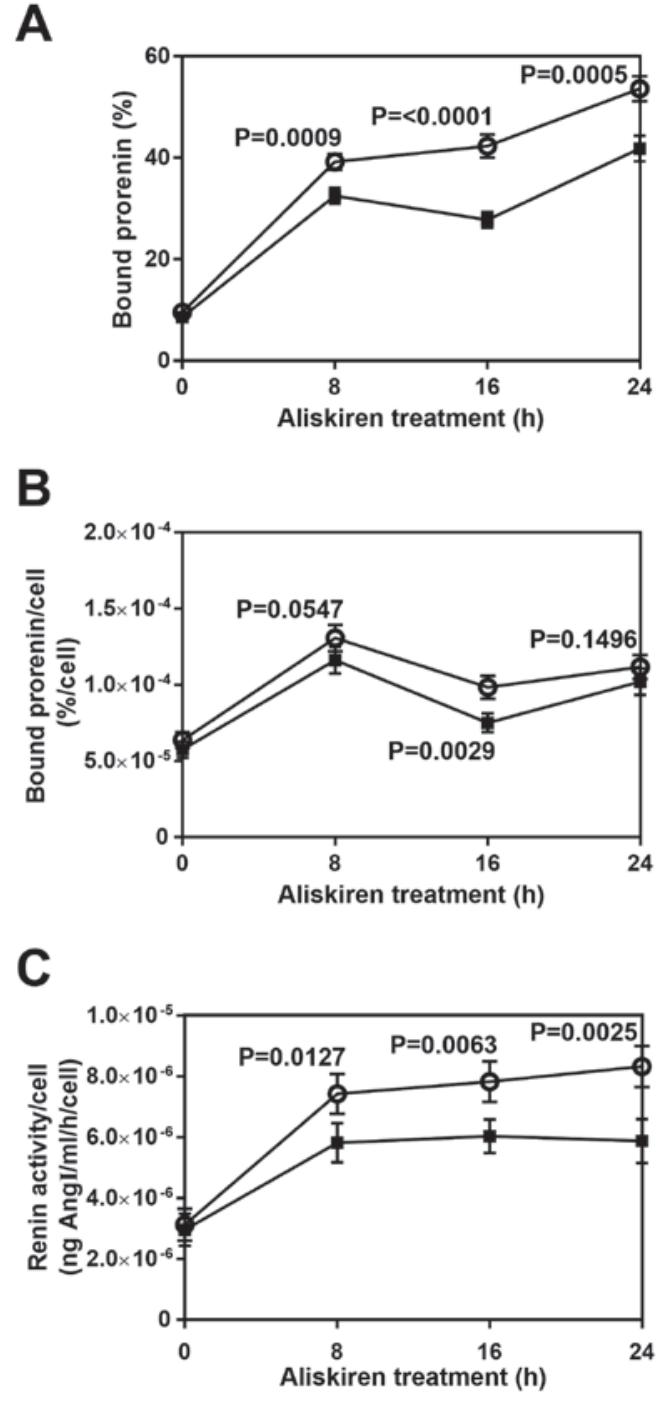

Figure 3. Effect of aliskiren on the cell-surface expression of full-length (P)RR. (A) Percentage of prorenin bound to the HUVEC membrane. The concentration of unbound prorenin in Medium-2 was determined by ELISA, and the bound prorenin was determined as described in the Materials and methods section. (B) Percentage of bound prorenin per HUVEC. The percentage of bound prorenin was divided by the cell number. (C) Renin activity per cell for aliskiren-treated cells and controls. The concentration of AngI in Medium-3 was determined by ELISA to calculate renin activity. Renin activity was divided by the cell number. Filled squares represent aliskiren-treated cells and open circles represent controls. Statistical differences were identified between aliskiren-treated cells and controls by a two-tailed unpaired Student's t-test with $\mathrm{P}<0.05$ as the limit of significance. HUVEC, human umbilical vein endothelial cell; AngI, angiotensin I; (P)RR, (pro)renin receptor.

membrane was estimated. Following aliskiren treatment for different durations $(0,8,16$ and $24 \mathrm{~h})$, cells were incubated with exogenous prorenin, and the quantity of bound prorenin was evaluated (Fig. 3A). Approximately 10 and $50 \%$ of the exogenous prorenin bound to control membranes after 0 and $24 \mathrm{~h}$ of treatment, respectively (Fig. 3A, open circles). The quantity of bound prorenin was significantly decreased with aliskiren treatment for $8-24 \mathrm{~h}(\mathrm{P}<0.001$; Fig. 3A, filled squares). Additionally, it was observed that the concentration of endogenous prorenin secreted by HUVECs was almost 1,000 times lower than that of exogenous prorenin (data not shown), indicating that endogenous prorenin would have a negligible 
A

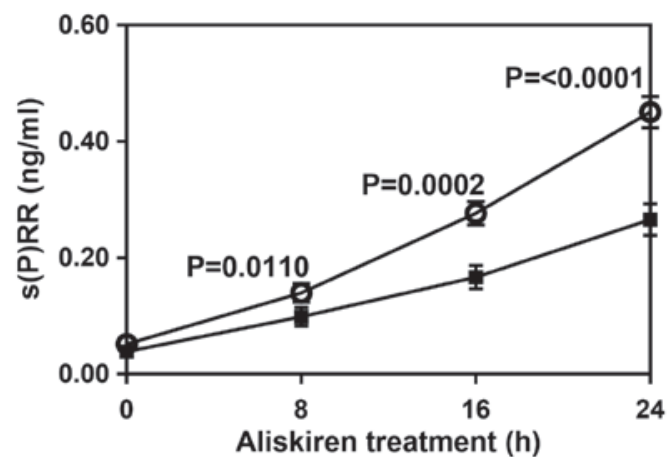

B

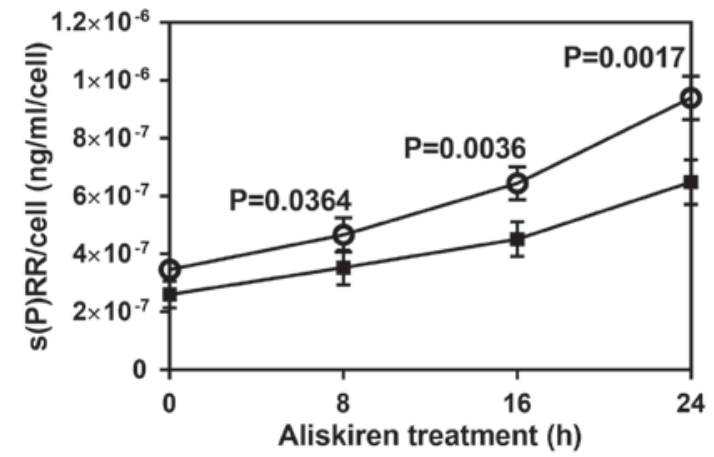

Figure 4. Effect of aliskiren on the level of $s(P) R R$ released from HUVECs. (A) Concentration of released $s(P) R R$. The concentration of $s(P) R R$ in Medium-1 was determined by sandwich ELISA. (B) S(P)RR concentration per HUVEC cell. s(P)RR concentration was divided by the cell number Filled squares represent aliskiren-treated cells and open circles represent controls. Statistical differences were identified between aliskiren-treated cells and controls by a two-tailed unpaired Student's t-test with $\mathrm{P}<0.05$ as the limit of significance. $\mathrm{s}(\mathrm{P}) \mathrm{RR}$, soluble (pro)renin receptor; HUVEC, human umbilical vein endothelial cell.

effect on the estimation of exogenous prorenin bound to HUVEC membrane. The quantity of bound prorenin per cell with aliskiren treatment was similar to that of untreated cells except at $16 \mathrm{~h}$, where significant difference was determined $(\mathrm{P}=0.0029$; Fig. 3B).

To further estimate the amount of full-length $(\mathrm{P}) \mathrm{RR}$ on HUVEC membranes, the renin activity of membrane-bound exogenous prorenin was measured. As reported previously $(1,30,31)$, the receptor-bound prorenin may become activated to exert renin activity, which can be estimated by measuring the production of AngI following incubation with sheep AOG (Fig. 1). In each condition $<3 \%$ total sheep AOG was utilized, which indicated that initial velocities of the renin-AOG reaction were estimated appropriately. The renin activity per cell of aliskiren-treated HUVECs was significantly lower than that of the control group by $8 \mathrm{~h}(\mathrm{P}=0.0127)$, and to the greatest extent at $24 \mathrm{~h}(\mathrm{P}=0.0025$; Fig. $3 \mathrm{C})$. After $8 \mathrm{~h}$ of treatment, both aliskiren-treated HUVECs and controls exhibited a plateau in renin activity per cell (Fig. 3C).

Effect of aliskiren on the level of $s(P) R R$ released from HUVECs. To examine the effect of aliskiren on the level of $\mathrm{s}(\mathrm{P}) \mathrm{RR}$ released, HUVECs were treated with or without the drug for different durations (0-24 h), and s(P)RR concentration was measured in the culture medium collected following treatment. Not only total $\mathrm{s}(\mathrm{P}) \mathrm{RR}$ concentration (Fig. 4A) but also s(P)RR concentration per cell (Fig. 4B) was significantly reduced by the treatment with aliskiren by $8 \mathrm{~h}(\mathrm{P}<0.05)$ and most notably at $16-24 \mathrm{~h}(\mathrm{P}<0.01)$.

\section{Discussion}

In the present study, HUVECs were used as an in vitro model to investigate the effect of aliskiren on the protein levels of full-length $(\mathrm{P}) \mathrm{RR}$ as well as $\mathrm{s}(\mathrm{P}) \mathrm{RR}$. To estimate its effect on the cell-surface expression of full-length $(\mathrm{P}) \mathrm{RR}$, exogenous prorenin as well as AOG were utilized. Previous studies have reported that the mannose-6-phosphate receptor present on the plasma membrane binds to renin and prorenin through oligosaccharide chains, and that this receptor binding to prorenin does not result in the generation of extracellular or intracellular angiotensin (for a review see ref. 24). In addition, the extracellular domain of (P)RR may take part in the activation of prorenin, thereby leading to renin activity in solution $(1,30)$ and on the cell surface $(1,31)$. In the current study, it was observed that exogenous prorenin could bind to the HUVEC membranes, and that renin activity was generated from membrane-bound prorenin. These results indicated that full-length $(\mathrm{P}) \mathrm{RR}$ is expressed on the cell surface of HUVECs.

When HUVECs were treated with aliskiren, the renin activity generated per cell was decreased. This result indicates that cell-surface expression of full-length $(\mathrm{P}) \mathrm{RR}$ is reduced by aliskiren treatment, which is consistent with a previous report (19). The observed plateau in the level of renin activity per cell suggests that HUVECs possess a given level of full-length $(\mathrm{P}) \mathrm{RR}$ on the cell membrane.

Our group previously reported that $\mathrm{s}(\mathrm{P}) \mathrm{RR}$ was released from HUVECs (20). From current results, it was suggested that the quantity of $\mathrm{s}(\mathrm{P}) \mathrm{RR}$ released from HUVECs was decreased by aliskiren treatment. To the best of our knowledge, this is the first report indicated that aliskiren, an anti-hypertensive drug, reduces the level of the soluble form of (P)RR. The current findings suggest that the protein levels of $s(P) R R$ may be decreased during anti-hypertensive treatments with aliskiren. Such a possibility should be considered when monitoring $\mathrm{s}(\mathrm{P}) \mathrm{RR}$ levels for the diagnosis of diseases.

A recent study reported that $\mathrm{s}(\mathrm{P}) \mathrm{RR}$ could exert antidiuretic functions and enhance urine concentrating capability by increasing the expression of renal aquaporin-2, which is involved in reabsorption of water (15). As indicated in the current study, the administration of aliskiren may instigate a decrease in the levels of $s(P) R R$, which would reduce reabsorption of water. Aliskiren may act via an alternative route for lowering blood pressure via aliskiren-induced reduction of $\mathrm{s}(\mathrm{P}) \mathrm{RR}$. The present findings provide novel insight into the efficacy of aliskiren. This hypothesis should be clarified by examining the effect of aliskiren on $s(P) R R$ levels as well as the $\beta$-catenin signaling that increases renal aquaporin-2 expression (15).

In conclusion, the quantity of $\mathrm{s}(\mathrm{P}) \mathrm{RR}$ appears dependent on the extent that $(\mathrm{P}) \mathrm{RR}$ is produced and processed in HUVECs. Further biochemical and clinical investigations are warranted to elucidate the underlying mechanisms in HUVEC, which should provide researchers with an understanding of how 
aliskiren changes the quantity of $\mathrm{s}(\mathrm{P}) \mathrm{RR}$, as a potential antidiuretic molecule and prospective disease biomarker.

\section{Acknowledgements}

Not applicable.

\section{Funding}

The current study was supported in part by a Grant-in-Aid for Scientific Research from the Ministry of Education, Science and Culture of Japan (grant no. 1907165) and by a Heisei 28 (Fiscal Year 2016) Health Science Center Foundation grant from the General Incorporated Foundation Health Science Center (Kanagawa, Japan).

\section{Availability of data and materials}

The data used and/or analyzed during the current study are available from the corresponding author on reasonable request.

\section{Authors' contributions}

SY analyzed the data, performed the statistical analysis and wrote the manuscript. KBB performed the experiments, analyzed the data and wrote the manuscript. AHMNN participated in the design of the study and analyzed the data. TN contributed to the writing of the manuscript. FS conceived the study and participated in its design and coordination. AE contributed to the coordination of the study, and helped write the manuscript. All authors edited the manuscript and approved the final version to be published.

\section{Ethics approval and consent to participate}

Not applicable.

\section{Consent for publication}

Not applicable.

\section{Competing interests}

The authors declare that they have no competing interests.

\section{Authors' information}

The present address of KBB is the Department of Research and Development, Ichimaru Pharcos Co., Ltd., 318-1 Asagi, Motosu, Gifu 501-0475, Japan. This study was undertaken independently of the current work of KBB.

\section{References}

1. Nguyen G, Delarue F, Burcklé C, Bouzhir L, Giller T and Sraer JD: Pivotal role of the renin/prorenin receptor in angiotensin II production and cellular responses to renin. J Clin Invest 109: 1417-1427, 2002.

2. Krop M, Lu X, Danser AH and Meima ME: The (pro)renin receptor. A decade of research: What have we learned? Pflugers Arch 465: 87-97, 2013.
3. Nabi AHMN, Biswas KB, Ebihara A, Nakagawa T and Suzuki F: Renin angiotensin system in the context of renin, prorenin, and the (pro)renin receptor. Rev Agric Sci 1: 43-60, 2013.

4. Kinouchi K, Ichihara A, Sano M, Sun-Wada GH, Wada Y, Kurauchi-Mito A, Bokuda K, Narita T, Oshima Y, Sakoda M, et al: The (pro)renin receptor/ATP6AP2 is essential for vacuolar H+-ATPase assembly in murine cardiomyocytes. Circ Res 107: 30-34, 2010.

5. Cruciat CM, Ohkawara B, Acebron SP, Karaulanov E, Reinhard C, Ingelfinger $\mathrm{D}$, Boutros $\mathrm{M}$ and Niehrs $\mathrm{C}$ : Requirement of prorenin receptor and vacuolar H+-ATPase-mediated acidification for Wnt signaling. Science 327: 459-463, 2010.

6. Kanda A, Noda K, Saito W and Ishida S: (Pro)renin receptor is associated with angiogenic activity in proliferative diabetic retinopathy. Diabetologia 55: 3104-3113, 2012.

7. Matavelli LC, Huang J and Siragy HM: (Pro)renin receptor contributes to diabetic nephropathy by enhancing renal inflammation. Clin Exp Pharmacol Physiol 37: 277-282, 2010.

8. Contrepas A, Walker J, Koulakoff A, Franek KJ, Qadri F, Giaume C, Corvol P, Schwartz CE and Nguyen G: A role of the (pro)renin receptor in neuronal cell differentiation. Am J Physiol Regul Integr Comp Physiol 297: R250-R257, 2009.

9. Shibayama Y, Fujimori T, Nguyen G, Hirose T, Totsune K, Ichihara A, Kitada K, Nakano D, Kobori H, Kohno M, et al: (Pro) renin receptor is crucial for $\mathrm{Wnt} / \beta$-catenin-dependent genesis of pancreatic ductal adenocarcinoma. Sci Rep 5: 8854, 2015.

10. Ludwig J, Kerscher S, Brandt U, Pfeiffer K, Getlawi F, Apps DK and Schägger H: Identification and characterization of a novel 9.2-kDa membrane sector-associated protein of vacuolar proton-ATPase from chromaffin granules. J Biol Chem 273: 10939-10947, 1998.

11. Cousin C, Bracquart D, Contrepas A, Corvol P, Muller L and Nguyen G: Soluble form of the (pro)renin receptor generated by intracellular cleavage by furin is secreted in plasma. Hypertension 53: 1077-1082, 2009.

12. Nakagawa T, Suzuki-Nakagawa C, Watanabe A, Asami E, Matsumoto M, Nakano M, Ebihara A, Uddin MN and Suzuki F: Site-1 protease is required for the generation of soluble (pro)renin receptor. J Biochem 161: 369-379, 2017.

13. Gonzalez AA, Lara LS, Luffman C, Seth DM and Prieto MC: Soluble form of the (pro)renin receptor is augmented in the collecting duct and urine of chronic angiotensin II-dependent hypertensive rats. Hypertension 57: 859-864, 2011.

14. Morimoto S, Ando T, Niiyama M, Seki Y, Yoshida N, Watanabe D, Kawakami-Mori F, Kobori H, Nishiyama A and Ichihara A: Serum soluble (pro)renin receptor levels in patients with essential hypertension. Hypertens Res 37: 642-648, 2014.

15. Lu X, Wang F, Xu C, Soodvilai S, Peng K, Su J, Zhao L, Yang KT, Feng Y, Zhou SF, et al: Soluble (pro)renin receptor via $\beta$-catenin enhances urine concentration capability as a target of liver $\mathrm{X}$ receptor. Proc Natl Acad Sci USA 113: E1898-E1906, 2016.

16. Wood JM, Maibaum J, Rahuel J, Grütter MG, Cohen NC, Rasetti V, Rüger H, Göschke R, Stutz S, Fuhrer W, et al: Structure-based design of aliskiren, a novel orally effective renin inhibitor. Biochem Biophys Res Commun 308: 698-705, 2003.

17. Pantzaris ND, Karanikolas E, Tsiotsios K and Velissaris D: Renin inhibition with aliskiren: A decade of clinical experience. J Clin Med 6: 6, 2017.

18. Feldman DL, Jin L, Xuan H, Contrepas A, Zhou Y, Webb RL, Mueller DN, Feldt S, Cumin F, Maniara W, et al: Effects of aliskiren on blood pressure, albuminuria, and (pro)renin receptor expression in diabetic TG(mRen-2)27 rats. Hypertension 52: 130-136, 2008

19. Ferri N, Greco CM, Maiocchi G and Corsini A: Aliskiren reduces prorenin receptor expression and activity in cultured human aortic smooth muscle cells. J Renin Angiotensin Aldosterone Syst 12: 469-474, 2011.

20. Biswas KB, Nabi AN, Arai Y, Nakagawa T, Ebihara A, Ichihara A, Inagami T and Suzuki F: Qualitative and quantitative analyses of (pro)renin receptor in the medium of cultured human umbilical vein endothelial cells. Hypertens Res 34: 735-739, 2011.

21. Nachman RL and Jaffe EA: Endothelial cell culture: Beginnings of modern vascular biology. J Clin Invest 114: 1037-1040, 2004.

22. Nasir UM, Takahashi K, Nagai T, Nakagawa T, Suzuki F and Nakamura Y: Two peaks in $\mathrm{pH}$ dependence of renin-angiotensinogen reaction. Biosci Biotechnol Biochem 62: 338-340, 1998.

23. Suzuki F, Hayakawa M, Nakagawa T, Nasir UM, Ebihara A, Iwasawa A, Ishida Y, Nakamura Y and Murakami K: Human prorenin has 'gate and handle' regions for its non-proteolytic activation. J Biol Chem 278: 22217-22222, 2003. 
24. Danser AH and Deinum J: Renin, prorenin and the putative (pro) renin receptor. Hypertension 46: 1069-1076, 2005.

25. Nagase M, Suzuki F, Sawai Y, Orihashi T, Inui Y, Nakagawa T and Nakamura Y: Purification and some properties of recombinant sheep angiotensinogen expressed in Chinese hamster ovary cells. Biomed Research Tokyo 18: 439-443, 1997.

26. Ebihara A, Nasir UM, Yoshida S, Kondou T, Nakagawa T, Fukamizu A, Suzuki F, Nakamura Y and Murakami K: Sialic acid residue of ovine angiotensinogen does not affect the reactivity to human renin. Biomed Research Tokyo 21: 105-109, 2000

27. Suzuki F, Yamashita S, Takahashi A, Ito M, Miyazaki S, Nagata Y and Nakamura Y: Highly sensitive microplate ELISA for angiotensin I using 3,3'5,5'tetramethylbenzidine. Clin Exp Hypertens A12: 83-95, 1990.

28. Nabi AH, Biswas KB, Nakagawa T, Ichihara A, Inagami $T$ and Suzuki F: Prorenin has high affinity multiple binding sites for (pro)renin receptor. Biochim Biophys Acta 1794: 1838-1847, 2009.
29. Ku HH: Notes Use Propag Error Formulas. J Res Natl Bur Stand 70C: 263-273, 1966.

30. Nabi AH, Kageshima A, Uddin MN, Nakagawa T, Park EY and Suzuki F: Binding properties of rat prorenin and renin to the recombinant rat renin/prorenin receptor prepared by a baculovirus expression system. Int J Mol Med 18: 483-488, 2006.

31. Nurun NA, Uddin NM, Nakagawa T, Iwata H, Ichihara A, Inagami T and Suzuki F: Role of 'handle' region of prorenin prosegment in the non-proteolytic activation of prorenin by binding to membrane anchored (pro)renin receptor. Front Biosci 12: 4810-4817, 2007. 